\title{
Forming An Innovative Exopreneurship Model To Achieve Strategic Goals
}

\author{
Mykola Danyliuk \\ Department of Applied Economics \\ Ivano-Frankivsk National Technical \\ University of Oil and Gas \\ Ivano-Frankivsk, Ukraine \\ http://orcid.org/0000-0003-1950-560X
}

\author{
Vitalina Babenko \\ International E-commerce and \\ Hotel\&Restaurant Business Department \\ V. N. Karazin Kharkiv National \\ University \\ Kharkiv, Ukraine \\ http://orcid.org/0000-0002-4816-4579 \\ Tetiana Oryshchyn \\ Department of Finance \\ Ivano-Frankivsk National Technical \\ University of Oil and Gas \\ Ivano-Frankivsk, Ukraine \\ https://orcid.org/0000-0002-2693-8094
}

\author{
Nataliia Krykhivska* \\ Department of Finance \\ Ivano-Frankivsk National Technical \\ University of Oil and Gas \\ Ivano-Frankivsk, Ukraine \\ https://orcid.org/0000-0001-6807-0177 \\ *Note: use * for corresponding author, not \\ strongly for the first author
}

\begin{abstract}
For the innovative breakthrough of the national economy it is necessary to formulate and implement a strategy of partnerships between the industrial, educational and scientific sphere of social activity. The implementation of this strategy is possible using the existing potential of the participants and the integration mechanisms of their interaction on the basis of exopreneurship. Exopreneurship diversifies the choice, and therefore increases the opportunity to choose the optimal direction for the development of entrepreneurial units. The implementation of the exopreneurship model as a result of the implementation of the partnership strategy is the foundation for ensuring the strategic sustainability of production structures. The algorithm is presented for implementation of the exopreneurship model formed in the common area of intersection of the three components of the "triangle of knowledge" - the zone of exopreneurship. It creates an innovative exopreneur unit, which is one of the important strategic tasks of innovative development of the state. This will enhance the importance of industrial potential for the modernization of the national economy, the strategic part of which is the oil and gas industry and to bring as close as possible the vectors of development of industrial, educational and scientific structures of this industry. The mathematical model of dependence of strategic stability of partners on the level of their partner potential is offered. This model has been tested on the materials of potential partners of three segments of partnerships with graphical presentation of results.
\end{abstract}

Keywords-exopreneurship, partnership, strategic stability, strategy, educational structures, scientific structures

\section{INTRODUCTION}

In view of the need for an innovative breakthrough in the domestic economic system, as an important component of the global economy, the search for new ways to develop entrepreneurship is important, among which the formation and implementation of a partnership strategy between the production, educational and scientific spheres of public activity occupies an important place. The base of this strategy should be the unification of these links of the "knowledge triangle" into a single integral system, the establishment of close relationships between them in order to effectively carry out functions and achieve their goals. In our opinion, its implementation is possible using the existing potential of the participants and the integration mechanisms of their interaction on the basis of ex-co-operation.

\section{REVIEW OF PUBLICATIONS}

Exopreneurship is a new notion that expands the model of entrepreneurship. The term "exopreneurship" can be found in foreign studies, where it is defined it as a part of the process of corporate entrepreneurship for the development of innovative activity of large organizations by obtaining ideas or innovations from external sources. Moreover, the external innovation can be acquired as franchising, strategic alliance, external capital venture, and subcontracting. In Ukraine, the definition of "exopreneurship" has been studied by the following scientists: L. Lipich and Yu. Grudevich, and in their scientific works $[1 ; 2]$ the essence of this concept is considered in the acquisition of innovations developed outside the company. The authors state that exopreneurship diversifies choice, and therefore increases the ability to choose the optimal direction of development.

In addition, attention is paid to the characteristics, among which are the following:

- the reason for the origin of exopreneurship is the presence of organizations that own ideas and technologies, cooperation with them makes possible to use resources more efficiently and accelerate achievement of the goal;

- exopreneurship is realized on the basis of partnerships with third-party organizations that own ideas and technologies. The nature of cooperation is determined by the choice of the implementation mechanism;

- exopreneurship involves cooperation with external partners, and participation of third-party organizations can be both minimal and quite significant;

- financing the exopreneurship program depends on the mechanism of cooperation chosen; 
- at least two partners with different levels of organization and management methods can participate in the implementation of the exopreneurship project;

- exopreneurship implies diversification of risks between project participants;

- to achieve a common goal the partners are forced to partially or completely change strategies in the case of exopreneurship;

- reduction of the costs of product implementation of exopreneurship is due to the use of the comparative advantages of the partners involved in the process, i.e. the possibility to choose an effective way of performing any function in the framework of a joint project.

\section{THE PURPOSE OF THE STUDY}

The purpose of this study is to substantiate the need to implement the model of exopreneurship in the process of ensuring the strategic sustainability of production structures. It should be mentioned that the scientific approaches to the interpretation of the category "strategic sustainability", make it possible to consider the strategic stability of the enterprise as a complicated, complex and multifaceted characteristic of the activity, reflecting its ability to maintain integrity and sustainable development under the influence of internal and external destabilizing factors, as well as achieving strategic goals for adapting an entity to a changing competitive environment with uncertainty.

In addition, it is determined that the content is revealed in the context of its components (industrial sustainability, financial sustainability, marketing sustainability, innovation and technological sustainability, social (personnel) sustainability and environmental sustainability), which are closely related with each other, forming the system of strategic stability. So, breach of a separate link in the system can lead to a failure of strategic stability in general.

Therefore, it can be stated that the basis for ensuring the strategic sustainability of an enterprise is the formation of an appropriate strategy for the activity, because it is a unifying mechanism of goals, opportunities (potential) and conditions (environment). The strategy helps the enterprise to choose its rational way of development and to create the most important advantages in its functioning: it prepares it for changes in the external environment; associates its resources with changes in the environment; clarifies problems that arise; coordinates the work of different structural departments; improves control at the enterprise [3].

It is the partnership strategy between the main components of the "knowledge triangle" that can act as a platform for transferring new knowledge from science to other types of economic activity and making enquiries for prospective research and training of highly qualified specialists in economic entities of different spheres of the national economy.

It should be noted that the convergence of education, science and production should solve the most urgent problems of the education system, including improving the quality and compliance of the training structure to the real needs of the labor market. The co-operation between the educational, research and entrepreneurial components of the domestic economic system will result in training more adapted and adaptable to work in changing environment and high levels of competition, capable of taking the initiative and taking responsibility. This will accelerate the solution of the issues of structural reform of the domestic economy, the formation of new high-tech innovative industries and will promote entrepreneurship. Strengthening the processes of interaction between higher education, science and innovative economic activity will also be a significant contribution to solving the problem of overcoming the systematic contradiction between the presence in Ukraine of a powerful scientific complex capable of producing world-class results and insufficient demand for Ukrainian scientists to develop from the domestic economy [4].

Unfortunately, educational, scientific and industrial structures, including the oil and gas industry, operate in parallel without close interaction, so the main goal of implementing a partnership strategy should be the balanced convergence of production, education and science to achieve mutual goals and to ensure the strategic sustainability of business entities.

\section{RESULTS}

For the introduction of the partnership strategy, the following algorithm is proposed for the implementation of the model of exopreneurship (Figure 1). The presence of a common intersection plane of the three components of the "knowledge triangle" should be defined as the "exopreneurship zone". However, we note that the larger the intersection of circles corresponding to the partner entities, the wider this area of common interest is.

Based on the abovementioned, it can be argued that the area of exopreneurship is formed as a result of the development of partnerships and is implemented in the form of the creation of a specialized structural unit. Therefore, there is a need to develop the basic foundations of creating an exopreneurship center, as a collegiate body of participants in partnerships, whose main task will be to generate, provide and support ideas and innovations, transfer of knowledge and technology.

In addition, within the functions of the exopreneurship center, a lot of attention should be paid to development of exopreneurship promotion, support of potential exopreneurs, creation exopreneurship units in accordance with the areas of cooperation, adjustment and monitoring of their activities, ensure protection of intellectual property.

One of the activities of the exopreneurship center is the creation and operation of a platform of ideas (projects) based on the systematization and preservation of scientific and innovative ideas that cannot be implemented in the near future. 


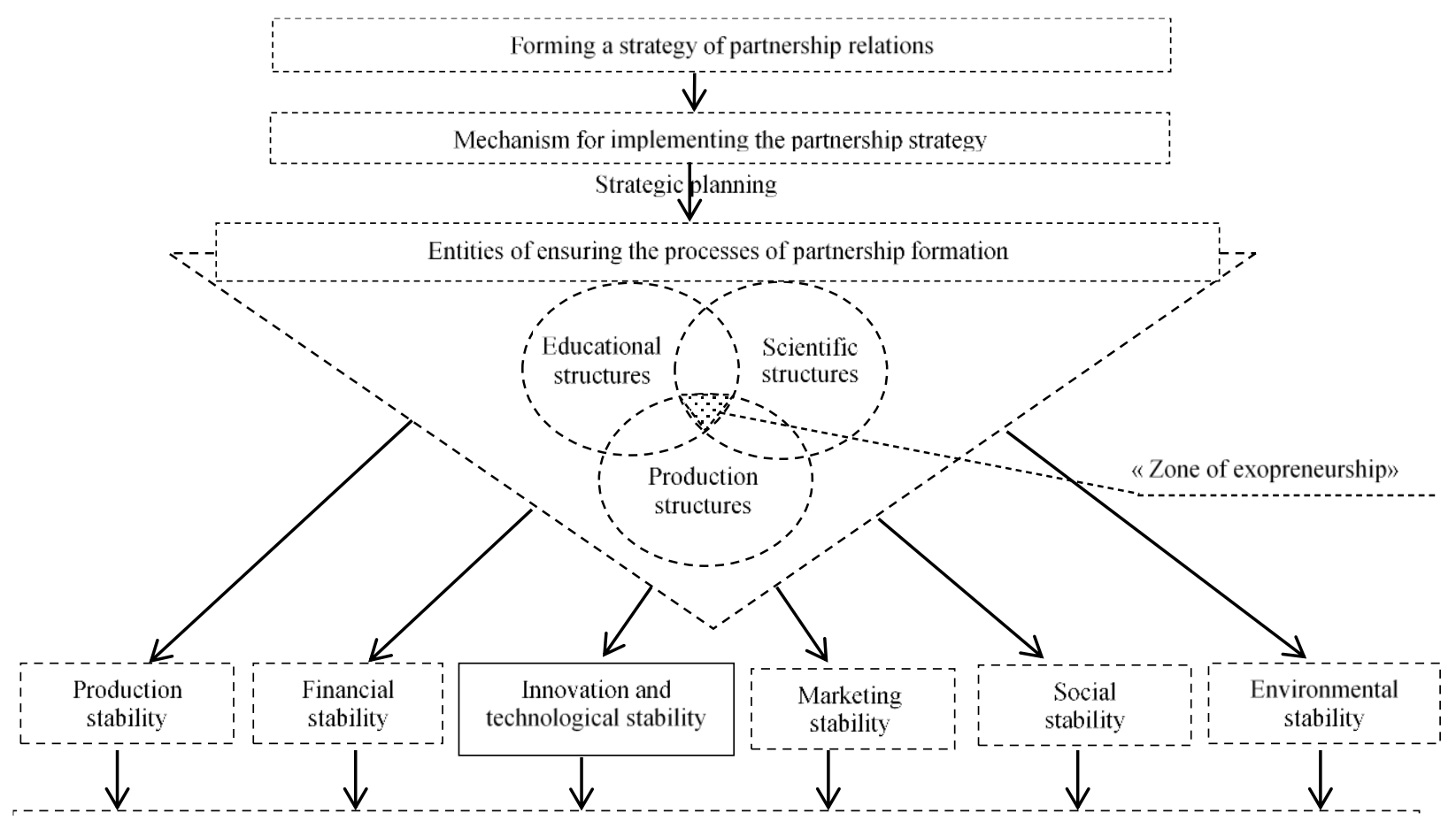

Fig. 1. Stages of providing strategic stability for production structures based on formation of the exopreneurship model

Source: developed by the authors.

It is also advisable to provide for the possibility of selling ideas and projects to interested parties of partnerships, which will allow to generate additional income as an alternative source of financing for the activity of the center.

Within each individual project or activity field in the exopreneurship area, an innovative exopreneur unit is formed, the result of which operation determines the impact on a specific component of strategic sustainability.

Consequently, it can be stated that the innovative structures formation is one of the important strategic tasks of innovative development of the state. This will enhance the role of industrial potential as a basis for modernizing the national economy.

An important strategic part of Ukraine's industrial potential is considered to be the oil and gas industry, which ensures the energy independence of the national economy and the functioning of all other industries. It plays a decisive role in forming the principles of the security of the state, ensuring economic development, both the state as a whole, and mining, metallurgy, agro-industrial and other industries. The volume of activity and strategic importance of the oil and gas sector in Ukraine is proved by the volumes of production of hydrocarbon raw materials during the years of independence of Ukraine, in particular more than 400 billion $\mathrm{m} 3$ of gas and 100 million tons of oil and gas condensate were produced, 2 trillion of gas, 800 billion $\mathrm{m} 3$ of gas and 1 billion 200 million tons of oil were transported throughout Ukraine [5].
It should be noted that the state of the oil and gas industry is extremely complicated today, which is caused by the significant influence of the factors destabilizing the development of the industry, among which the following are highlighted $[6 ; 7]$ the high level of monopolization of the gas market by the state; the absence of independent companies in the gas market of Ukraine and appropriate competition mechanisms; dependence of Ukraine's gas market on external political factors; high energy consumption of production; significant level of moral and physical deterioration of fixed assets of oil and gas complex enterprises; shortage of qualified personnel; market fluctuations in oil and gas prices; lack of payment discipline of consumers regarding payments for supplied and consumed gas and others.

Insufficient supply of the domestic economy with its own energy resources undoubtedly results in the energy, and thus the economic and political dependence of the country on imported supplies. Much of the country's oil and gas fields are in the final stages of development, and deeper are the productive horizons of hydrocarbon production. Accordingly, a large proportion of oil and gas is attributed to heavy production. This situation requires changes in the system of managing the activity of oil and gas companies and finding new innovative methods to enter the sector on the path of intensive development.

The efficiency of the powerful enterprises of the oil and gas complex largely depends on the modern scientific support of the activity and the intellectual qualities of the personnel. Therefore, it is important to review the relationship between the oil and gas industry, research and 
development institutions and industry-specific high schools when new approaches to partnerships aimed at ensuring the strategic sustainability of the participating partners will emerge instead of the established relationships established in the past. In particular, foreign scientific studies [8-10] indicate a positive experience of convergence between educational institutions and business structures on the basis of models entrepreneurship education.

Accordingly, the formation and implementation of a partnership strategy that combines targeted and integrated approaches allows setting goals and objectives of cooperation, identifying the available (potential) partners and using them to achieve the expected results.

At the same time, the implementation of the partnership strategy, in particular regarding the structures of the oil and gas industry, should provide for the following main tasks: formation of activity direction of partners in the framework of partnership cooperation; establishing the specific role of each partner and its structural unit in the strategy implementation; determining the size and methods of sharing resources, risks and responsibilities between the parties to the partnership; control and monitoring the implementation of the strategy and decision-making regarding further interaction between the parties.

It is determined that the dominant factor of success of any economic entity or country in the medium and long term is the ability to generate knowledge and to implement the latest technologies in production as efficiently as possible [11] Therefore, the basis for the formation and implementation of a partnership strategy is to channel the potential of the participating structures to obtain a synergistic effect, which is achieved through the cooperation of resources, information, experience, databases, the use of shared infrastructure, qualifications and skills of staff.

To establish the relationship between the strategic stability of production, educational and scientific structures from the level of their partner potential by mathematical modelling, we proposed the model [12], expressed by the system of differential equations (Formula 1):

$$
\left\{\begin{array}{l}
\frac{d x}{d t}=p_{1}(A-x)+p_{2} y+p_{3} z \\
\frac{d y}{d t}=p_{4}(B-y)+p_{5} x \\
\frac{d z}{d t}=p_{6}(C-z) y+p_{7}(C-z)+p_{8}(B-y)
\end{array}\right.
$$

where $x$ - the level of partnership potential of production structures, part of units;

$y$ - the level of partnership potential of educational structures, part of units;

$z$ - the level of partnership potential of scientific structures, part of units;

$\mathrm{t}$ - the conditional unit of time.
$A$; $B ; C$ - maximum values of the level for partnership potential of production, educational and scientific structures, at which their further development is impossible;

$p_{1}$ - the ratio of proportion between the level of partner potential of production structures and the rate of its level change;

$p_{2}$ - the ratio of proportion between the level of partnership potential of production structures and the rate of the level change of partner potential of educational structures;

$p_{3}-$ the ratio of proportion between the level of the partnering capacity of the production structures and the rate of the level change for the partnering capacity of the educational structures;

$p_{4}$ - the ratio of proportion between the partnership potential level of production structures and the rate of its level change;

$p_{5}$ - the ratio of proportion between the level of the partnering capacity of the educational structures and the change rate of the partnering capacity of the industrial structures;

$p_{6}$ - the ratio of proportion between the level of partnership potential of scientific structures and the change rate of the level for partnership potential of scientific and industrial structures;

$p_{7}$ - the ratio of proportion between the level of partnership capacity of scientific structures and the rate of its level change;

$p_{8}$ - the ratio of proportion between the level of partnership capacity of scientific structures and the rate of change for the level of partner potential of educational structures.

Using the method of data identification, the values of the proportion ratios $\left(p_{1}-p_{8}\right)$. Experts were interviewed on the level of influence of development one sector of the "knowledge triangle" on another, as an initial approximation variant (Formula 2):

$$
\left\{\begin{array}{l}
\frac{d x}{d t}=0.3(2-x)+0.3 y+0.3 z \\
\frac{d y}{d t}=0.5(2-y)+0.15 x \\
\frac{d z}{d t}=0.3(2-z) y+0.15(2-z)+0.3(2-y)
\end{array}\right.
$$

According to the analytical studies carried out on the example of the oil and gas industry enterprises, for the production component the arithmetic mean value of the aggregate partnership's potential was obtained at the level of 0.58 , which was determined by the initial and for the educational and scientific component, i. $\mathrm{ex}_{0}=0,58 ; \mathrm{y}_{0}=0,58$; $\mathrm{z}_{0}=0,58$.

The calculation for the proposed model was carried out using the Mathcad computer aided design system, and the results of prediction are presented in Figure 2. 


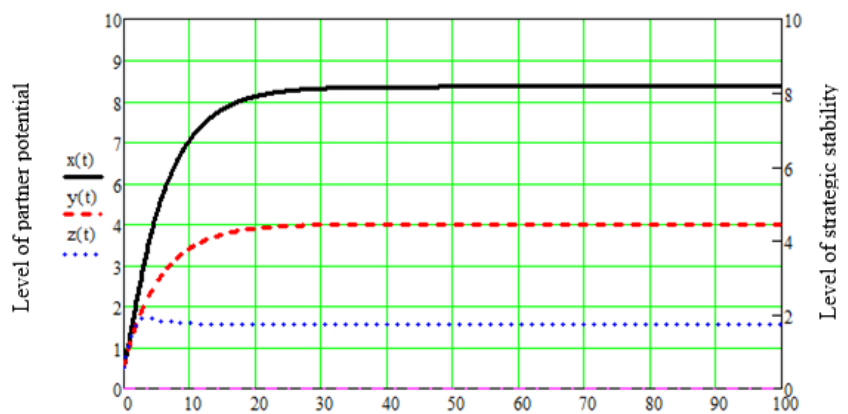

Fig. 2. Prediction the dependence of strategic stability of production, educational and scientific structures on the level of partner potential

As you can see, the proposed model determines the feasibility of implementing a partnership strategy, the result of which is to ensure the strategic stability of the participants of the interaction, as evidenced by a time interval of 30-100 conventional units.

One of the principles of implementing a partnership strategy between production, educational and scientific structures is the effect of synergistic interaction arising from Formula 2. The mathematical expression is represented by Formulas 3-5:

$$
\begin{gathered}
\Delta E_{C}^{B}=0.3 y+0.3 z \\
\Delta E_{C}^{O}=0.15 x \\
\Delta E_{C}^{H}=0.3(2-z) y+0.3(2-y)
\end{gathered}
$$

The obtained additional synergistic effect by all participants of the partnership relations is confirmed in Fig. 2. In particular, the achievement of the greatest synergistic effect is observed with respect to production structures.

The total interaction effect is defined as the sum of the additional effects of each partner in particular:

$$
\Delta E_{C}^{3}=\Delta E_{C}^{B}+\Delta E_{C}^{O}+\Delta E_{C}^{H}
$$

The creation of innovative units should be the result of strategic partnerships, which is confirmed by the presence of synergistic effect. Such a process is long-lasting, and therefore, in our opinion, their formation should be carried out as a result of the implementation of a partnership strategy.

\section{CONCLUSIONS}

Therefore, one of the goals of the country's innovation development strategy is to develop effective mechanisms for the creation, dissemination and transfer of knowledge and technology into production processes by maximizing the approximation of production, education, and science development vectors.

As a result of the research, it should be noted that the formation and functioning of the area of exopreneurship and the establishment of the center of exopreneurship - the main body of coordination and monitoring of activities as a result of strategic partnership cooperation of production structures of the oil and gas complex with educational and scientific structures should provide for a developed strategy of partnership. Exopreneurship, includes the development of ideas and innovations with the involvement of external participants and resources, enhances the innovative development of enterprises.

Approval of the model of dependence strategic stability on the level of partnership potential, confirms the feasibility of implementing a partnership strategy. The strategic stability of the partner entities by a time interval of 30-100 conventional units is ensured and additional synergistic interaction effect is obtained. So, according to the results of the study, it can be argued that this approach to the formation of strategic partner relations between industrial, educational and scientific structures should ensure optimization of the use of the potential of the partner, formation of information support between them, achievement of the planned goals and synergistic effect of interaction.

\section{REFERENCES}

[1] Yu. I. Hrudzevych, "The essence, origin and difference of the concepts of intrapreneurship and exoprenism", Scientific Bulletin of Kherson State University. Edition: Economic Sciences, Issue. 2, pp. 79, 2013. [in Ukrainian].

[2] L. H. Lipych, and Yu. I. Hrudzevych, "Organizational principles of creation and functioning of effective structures of support and development of intrapreneurship at machine-building enterprises", Theoretical and Practical Aspects of Economics and Intellectual Property: collection of scientific works. Mariupol, 2016, Issue 14, pp. 260-268. [in Ukrainian].

[3] O. V. Kravchenko, "The concept of enterprise development strategy", Bulletin of Sumy National Agrarian University, № 1(22), p. 267-272, 2010. [in Ukrainian].

[4] A. Yu. Ishchenko, "Innovative research universities as a factor in modernizing the educational and scientific sphere and building a knowledge society", URL: http://www.niss.gov.ua/articles/1427/.

[5] "Naftogaz of Ukraine" Joint Stock Companya. URL: http://www.naftogaz.com.

[6] L. T. Horal, T. I. Voitkiv, and I. B. Polych, "Development of a gas cluster under conditions of budgetary decentralization", Financial Aspects of Innovative Development of the Oil and Gas Complex of Ukraine: A Collective Monograph, For the title. edited by L. T. Horal and I. H. Fadeieva. Ivano-Frankivsk: IFNTUOG, 2016. 326 p.

[7] I. V. Protsiuk, "Factors of formation of crisis potential of oil and gas enterprises”, Economic Development Strategy of Ukraine, № 32, pp. 123-131, 2013. [in Ukrainian].

[8] P. Krpálek, and K. Krpálková Krelová, "Possibilities for Developing Business Potential in Economic Education", Examples of Implementation in Slovakia and the Czech Republic, Economics and Sociology, Vol. 9, No 4, pp. 119-133, 2016. DOI: 10.14254/2071789X.2016/9-4/7

[9] P. Premand, S. Brodmann, R. Almeida, R. Grun, and M. Barouni, "Entrepreneurship Education and Entry into Self-Employment Among University Graduates", World Development, Vol. 77, Jan. 2016, pp. 311-327, ISSN 0305750X, DOI: 10.1016/j.worlddev.2015.08.028, Publisher: Elsevier Ltd.

[10] M. Hoppe, "Policy and entrepreneurship education", Small Business Economics, Vol. 46, Issue 1, 1 January 2016, pp. 13-29, Publisher: Springer New York LLC, ISSN: 0921898X, DOI 10.1007/s11187015-9676-7.

[11] V. Babenko, V. Sidorov, Y. Koniaieva, and L. Kysliuk, "Features in scientific and technical cooperation in the field of non-conventional renewable energy", Global Journal of Environmental Science and Management, 5(SI): 105-112, 2019. DOI: 10.22034/GJESM.2019. 05.SI.12

[12] A. P. Oliinyk, M. V. Krykhivskyi, and N. O. Krykhivska, "Modelling the Interrelationship of Strategic Sustainability of Partner Entities" Business Inform, № 3, pp. 122-128, 2019. [in Ukrainian]. 